\title{
EVALUASI KUALITAS AIR WADUK BERDASARKAN PARAMETER FISIKA
}

\author{
Erwin Gustianta ${ }^{1}$, Rachmasari Pramita Wardhani ${ }^{2}$ \\ Universitas Tridharma \\ ${ }^{1}$ PDAM Litbang, ${ }^{2}$ Program Studi Teknik Mesin, Fakultas Teknik
}

\begin{abstract}
Abstrak
Waduk adalah sebuah bangunan besar yang dibuat oleh manusia dengan membendung sungai (Wetzel,2001). Waduk juga merupakan sistem peralihan (intermediet system) antara sungai (lotic waters) dan danau (lentic waters). Pembuatan waduk pada umumnya mempunyai tujuan dan fungsi, salah satunya untuk kebutuhan air baku dari pengolahan air minum. Waduk MG merupakan sumber air baku utama bagi PDAM Kota Balikpapan. Waduk MG merupakan sumber daya akuatik yang sangat penting ditinjau dari fungsi ekologis serta fungsi ekonomis. Oleh karena itu harus tetap terjaga baik dari segi kuantitas maupun kualitasnya. Dengan adanya berbagai aktivitas manusia di sekitar Waduk MG, maka akan mempengaruhi kondisi dari waduk tersebut.
\end{abstract}

Kata kunci- evaluasi, kualitas, fisika, suhu, transparansi, daya hantar listrik

\begin{abstract}
Reservoir is a large building made by humans by damming a river (Wetzel, 2001). Reservoirs are also an intermediate system between rivers (lotic waters) and lakes (lentic waters). The manufacture of reservoirs generally has objectives and functions, one of which is for raw water needs from drinking water treatment. MG Reservoir is the main source of raw water for PDAM Balikpapan City. MG Reservoir is a very important aquatic resource in terms of its ecological and economic functions. Therefore it must be maintained both in terms of quantity and quality. With the existence of various human activities around MG Reservoir, it will affect the condition of the reservoir.
\end{abstract}

Keywords - evaluation, quality, physics, temperature, transparency, electrical conductivity

\section{PENDAHULUAN}

Waduk adalah sebuah bangunan besar yang dibuat oleh manusia dengan membendung sungai (Wetzel,2001). Waduk juga merupakan sistem peralihan (intermediet system) antara sungai (lotic waters) dan danau (lentic waters). Pembuatan waduk pada umumnya mempunyai tujuan dan fungsi, salah satunya untuk kebutuhan air baku dari pengolahan air minum. Waduk MG merupakan sumber air baku utama bagi PDAM Kota Balikpapan. Waduk MG merupakan sumber daya akuatik yang sangat penting ditinjau dari fungsi ekologis serta fungsi ekonomis. Oleh karena itu harus tetap terjaga baik dari segi kuantitas maupun kualitasnya. Dengan adanya berbagai aktivitas manusia di sekitar Waduk MG, maka akan mempengaruhi kondisi dari waduk tersebut. Waduk MG memiliki kapasitas tampung kotor sebesar 16,30 juta m3. Berdasarkan dari pengamatan tahun sebelumnya (Laporan Litbang PDAM Kota Balikpapan Tahun 2012), kondisi kualitas fisik secara kimia dari air Waduk MG memerlukan perhatian yang lebih karena mengalami penurunan kualitas. 
Berdasarkan nilai total dari unsur kimia $\mathrm{P}$ (Fosfor) dan $\mathrm{N}$ (Nitrogen) yang dijadikan parameter bahwa Waduk mengalami pencemaran dalam skala ringan. Aktivitas warga di sekitar wilayah Waduk diperkirakan turut mempengaruhi kondisi perairan Waduk itu sendiri.

Untuk dapat memperbaiki mutu air baku diperlukan data-data dari faktor yang berpengaruh terhadap mutu air baku tersebut. Mutu air baku tidak saja dipengaruhi oleh faktor yang ada di waduk tapi juga oleh keadaan di sekitar waduk, untuk itu perlu diketahui bagaimana keadaan ekosistem yang ada di dalam maupun yang ada di sekitar waduk tersebut.

Kualitas air baku di Waduk MG selalu dipantau secara periodik oleh bagian Produksi PDAM Kota Balikpapan khususnya subbagian Sumber Air Baku bekerjasama dengan bagian QHSE. Selain di daerah genangan waduk, perlu juga mengetahui kualitas air yang berada di hulu sungai. Hal ini dilakukan agar setiap perubahan-perubahan yang terjadi pada kualitas air waduk dapat diketahui secara cepat dan jika terjadi penurunan kualitas air baku dapat diambil tindakan penanganan yang optimal. Berbagai aktivitas masyarakat yang ada di sekitar perairan sungai juga dapat memberikan beban masukan (constituent) bagi perairan Waduk MG. Beban masukan (constituent) tersebut akan menjadi sumber penambahan unsur hara perairan yang juga dapat menyebabkan terjadinya berbagai masalah perairan, seperti proses eutrofikasi yang terjadi ketika beban masukan tersebut berlebihan menyebabkan turunya kualitas air, sehingga akan mengganggu kehidupan fitoplankton sebagai produsen primer perairan. Selain itu beban masukan tersebut juga dapat menyebabkan terjadinya sedimentasi bisa berupa pertikel-partikel tanah dan sebagainya yang terbawa sebagai akibat erosi yang terjadi di daerah hulu. Akibatnya akan menyebabkan turunnya lapisan produktif perairan dan dapat mempersingkat usia pelayanan waduk. Berdasarkan hal tersebut maka karya ilmiah ini menelaah mengenai Evaluasi Kualitas Air Waduk Berdasarkan Parameter Fisika. Yang dibahas pada parameter fisika yaitu hanya berdasarkan suhu, transparansi (penetrasi cahaya) dan daya hantar listrik (DHL)

\section{METODE PENELITIAN}

Data-data kuantitatif diambil langsung dari lokasi perencanaan, Pengambilan Sampel di lapangan melibatkan beberapa personil yaitu PDAM dari bagian Litbang, Laboratorium, Sumber Air dibantu personil dari tenaga harian dan Badan Pengelola DAS. Titik pengambilan sampel air waduk ditentukan berdasarkan debit air yang diatur. pengambilan sampel dilakukan dengan tahapan sebagai berikut :

1. Siapkan alat pengambilan contoh yang sesuai dengan keadaan sumber airnya.

2. Penentuan lokasi diambil dengan bantuan alat GPS dan Peta Situasi Waduk MG.

3. Bersihkan alat pengambil sampel dengan air yang akan diambil, sebanyak 3 (tiga) kali dengan menggunakan air bersih.

4. Ambil contoh sesuai dengan peruntukan analisis dan campurkan kedalam wadah sampel, kemudian aduk hingga merata.

5. Masukkan air sampel kedalam wadah sampel yang disesuaikan dengan peruntukan analisis.

6. Lakukan sesegera mungkin pengujian pada sampel tersebut untuk mengetahui suhu, kekeruhan dan daya hantar listrik, $\mathrm{pH}$ dan oksigen terlarut. Dimana dari semua parameter tersebut air sampel dapat berubah dengan cepat dan tidak dapat diawetkan/didiamkan pada waktu yang relatif lama.

7. Hasil pengujian parameter lapangan dicatat dalam buku catatan khusus.

8. Pengambilan contoh untuk parameter pengujian di laboratorium dilakukan pengawetan air sampel.

Menurut Effendi, 2003, Titik pengambilan sampel air waduk ditetapkan menurut ketentuan-ketentuan sebagai berikut :

1. Pada waduk dengan kedalaman kurang dari 10 m, sampel air diambil dari 2 (dua) 
titik, yaitu dipermukaan dan didasar waduk.

2. Pada waduk dengan kedalaman antara 10 m - 30 m, sampel diambil pada 3 (tiga) titik, yaitu di permukaan, lapisan termoklin, dan di dasar waduk.

3. Pada waduk dengan kedalaman antara 30 m - 100 m, sampel diambil pada 4(empat) titik, yaitu di permukaan, lapisan termoklin (metalimnion), diatas lapisan hipolimnion, dan di dasar waduk.

4. Pada waduk dengan kedalaman lebih dari $100 \mathrm{~m}$, titik pengambilan sampel air dapat diperbanyak sesuai dengan keperluan.

Pengambilan sampel air dapat dilakukan melalui langkah-langkah kerja berikut :

$\checkmark$ Disiapkan alat pengambilan sampel yang sesuai dengan keadaan sumber air.

$\checkmark$ Alat-alat tersebut dibilas sebanyak 3 (tiga) kali dengan sampel air yang akan diambil.

$\checkmark$ Dilakukan pengambilan sampel sesuai dengan keperluan, sampel yang diperoleh dicampur secara merata di dalam penampungan sementara.

$\checkmark$ Jika pengambilan sampel dilakukan pada beberapa titik maka volume sampel dari setiap titik harus sama.

Setelah pengambilan sampel, air sampel sebaiknya segera dianalisis. Jika terpaksa harus disimpan, setiap parameter kualitas air memerlukan perlakuan tertentu terhadap sampel. Selain perlakuan dengan bahan kimia, pengawetan yang paling umum dilakukan adalah pendinginan pada suhu 40C selama tranportasi dan penyimpanan. Pada suhu tersebut, aktivitas bakteri terhambat.

\section{HASIL DAN PEMBAHASAN}

Sesuai dengan tujuan awal, yaitu untuk mengetahui kualitas air sesuai dengan parameter yang telah ditentukan, maka hasil tersebut di bandingkan dengan ketentuan standar air baku yang ada. Penentuan kualitas air baku didasarkan pada Peraturan Pemerintah Nomor 82 tahun 2001, Kelas 1 yang diperuntukan untuk air baku dan air minum.
Parameter Fisika

1. Suhu

Pengukuran suhu air dilakukan pada sampel air dalam wadah sampel kapasitas 1 liter.

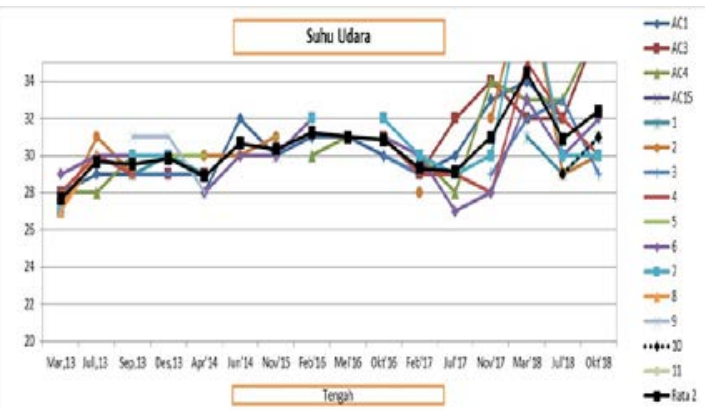

Gambar 1 Grafik Suhu Udara Waduk MG Sumber : Lab.PDAM Kota Balikpapan

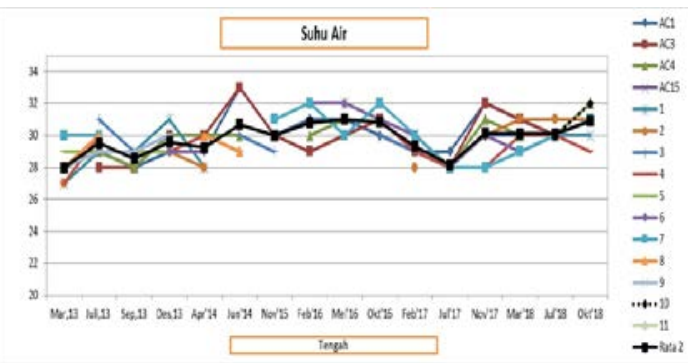

Gambar 2 Grafik Suhu Air Waduk MG Sumber : Lab.PDAM Kota Balikpapan

Pada gambar grafik 1 dan gambar grafik 2 . tahun 2018 rata-rata perubahan suhu air sama dengan perubahan suhu udara. Penurunan suhu terjadi pada bulan juli 2018 suhu air mencapai rata-rata $30,10^{\circ}$ namun kembali meningkat pada bulan November 2018 pada kisaran rata-rata 30,90 $90^{\circ}$ pada tahun 2018 suhu rata-rata air pada saat pengambilan sampel adalah $30^{\circ}$.

2. Tranparansi (Penetrasi Cahaya).

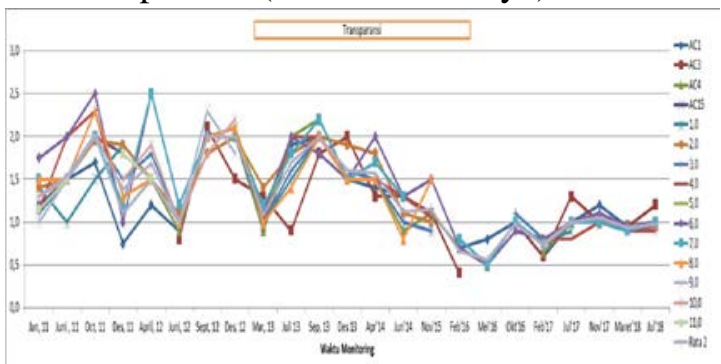

Gambar 3 Grafik Transparansi Air Waduk MG Sumber : Lab.PDAM Kota Balikpapan 
Pengukuran Transparansi di Waduk MG dilakukan dengan mengunakan keping disk berwarna hitam putih (Secchi Disk) yang kemudian diikat dengan tali yang telah diberi ukuran panjang. Berdasarkan data-data pengambilan sampel air waduk cenderung menurun mulai dari september 2013 sampai dengan mei 2016. Tahun 2016 tingkat transparasi menurun hingga rata-rata 0.3 terjadi pada bulan Februari 2016 dan pada bulan Mei 2016 tingkat transparasi air waduk kembali menurun dengan rata-rata $0,2 \mathrm{~m}$, angka ini sangat rendah jika dibandingakan dengan tahun-tahun sebelumnya, tetapi tingkat transparasi mengalami peningkatan pada bulan Oktober 2016 berkisar antara 0,9 - 1,10 m dengan rata-rata 0,6 m, pada tahun 2017 tranparasi waduk memiliki rata-rata berkisar antara 0,7 - 1,1. Pada tahun 2018 tingkat transparasi pada waduk manggar cenderung stabil yaitu pada kisaran 1,0.

\section{Daya Hantar Listrik (DHL)}

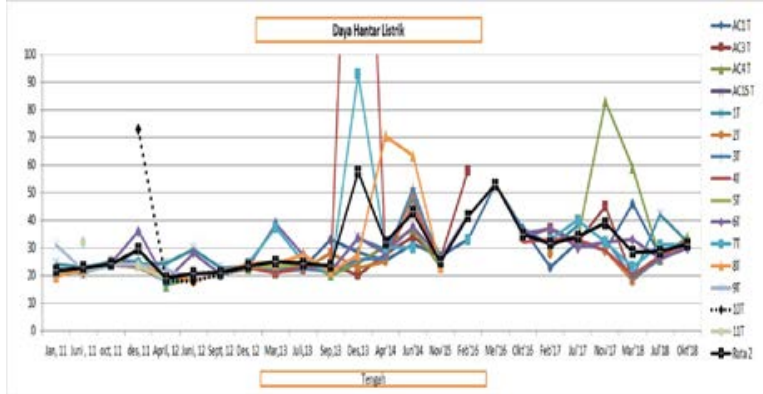

Gambar 4. Grafik Daya Hantar Listrik (DHL) Air Waduk MG (Tengah)

Sumber: Lab.PDAM Kota Balikpapan.

Pada Tahun 2016 tingkat fluktuasi kembali mengelami kenaikan secara keseluruhan rata-rata 56,20 mhos/Cm pada bagian dalam kemudian terus mengalami kenaikan pada bulan juli 2017.

Pada tahun 2018 tingkat fluktuasi DHL pada bagian tengah dan dalam mengalami peningkatan pada setiap pengambilan sampelnya dengan kidaran ratarata 28,44 - 31,33 mhos/Cm pada bagian tengah dan 28,11 - 48,10 mhos/Cm pada bagian dalam.
Evaluasi Waduk

Tingkat kecerahan atau transparansi di waduk mg secara fluktuatif bergerak naik dan turun pada kisaran 0,9 sampai dengan $1 \mathrm{~m}$. Selama pengamatan 2018 nilai terendah terjadi bada bulan Maret 2018. Hal ini dipengaruhi karena penetrasi cahaya dan berhubungan dengan warna pada bulan tersebut yang baik sehingga air waduk lebih jernih, karena waduk tidak mendapat tambahan dari bahan buangan baik dari sungai maupun air hujan yang membawa erosi tanah yang menyebabkan naiknya padatan terlarut. Hal ini terlihat dari kenaikan nilai padatan terlarut pada bulan Febuari 2018.

Transparansi pada bulan Juli dan Oktober 2018 cenderung meningkat dan stabil yaitu $1,0 \mathrm{~m}$. disini terjadi kejanggalan intensitas hujan pada bulan juli dan oktober 2018 cukup tinggi dengan nilai 231,70 mm namun transparansi cukup bagus.

Sedangkan pada bagian dasar waduk, padatan terlarut cenderung naik setiap bulannya, hal ini menandakan semakin banyaknya endapan sedimentasi di dasar waduk. Partikel terlarut maupun bahan sedimen yang berukuran sangat halus dan sebagian berupa koloidal maupun ion-ion logam yang berasal dari limbah rumah tangga atau industri ini memicu kenaikan daya hantar listrik yang setiap tahunya cenderung meningkat pula.

\section{KESIMPULAN}

Kesimpulan dari hasil analisa dan bahasan:

1. Tahun 2018 rata-rata perubahan suhu air sama dengan perubahan suhu udara.

2. Dilihat kencenderungan selama dua tahun waduk manggar berfluktuatif naik turun stabil. Namun demikian penurunan kualitas / tercemar pasti terjadi, terutama pada saat intensitas hujan tinggi hal ini dikarenakan hujan membawa unsur-unsur dipermukaan ke waduk.

3. Ttingkat fluktuasi DHL pada bagian tengah dan dalam mengalami 
peningkatan pada setiap pengambilan sampelnya.

4. Adanya pembangunan jalan Tol di sekitar waduk di khawatirkan dapat mempengaruhi kualitas waduk serta mengakibatkan sedimentasi di waduk manggar.

\section{SARAN}

Mengingat waduk manggar merupakan sumber air baku utama bagi masyarakat, maka diperlukan upaya pengelolaan wilayah perairan di ulu dan hilir waduk seperti,

1. Pengawasan dan pengendalian terhadap kegiatan perkebunan, pertanian perikanan dan aktifitas lainya di sekitar perairan waduk.

2. Monitoring kualitas air waduk manggar dan sungai, termasuk buangan limbah industri dan rumah tangga.

3. Penghijauan di daerah perairan sungai dan waduk manggar seperti dengan tanaman bambu yang bisa menyimpan cadangan air.

4. Pengelolaan lahan basah di sekitar waduk.

\section{UCAPAN TERIMA KASIH}

Penulis mengucapkan terima kasih kepada perusahaan dan berbagai pihak yang mendukung penelitian ini.

\section{DAFTAR PUSTAKA}

Krismono, A.S.N. dan Kartamihardja, S. 1995. Status trofik perairan Waduk Kedungombo, Jawa Tengah, sebagai dasar pengelolaan perikanannya. Jurnal Perikanan Indonesia 1 (3): 26 35.

Wetzel, R.G. (2001) Limnology Lake and Reservoir Ecosystems. Academic Press, San Diego. Vol.5 No.4, April 19, 2018 Vol.5 No.4, April 19, 2018.
Barnes, R.S.K. dan K.H. Mann. 1994. Fundamentals of Aquatic Ecology. Oxford: Blackwell Scientific Publication.

Boehme, M. 2000. Primary Production in Stream dan River. http://www.germany.edu/boehme.

Folkowski, P.G. dan A. J. Raven. 1997. Aquatic Photosynthesis. New York: Blacwell Science-USA.

Jones, R.I. dan R.C. Francis. 1982. Dispersion patterns of phytoplankton in lakes. Hydrobiologia 86 (1-2): 21-28. 